\title{
Small-scale non-linear geostatistical analysis of Liocarcinus depurator (Crustacea: Brachyura) abundance and size structure in a western Mediterranean population
}

\author{
Marta M. Rufino ${ }^{1,2, *}$, Francesc Maynou ${ }^{1}$, Pere Abelló ${ }^{1}$, Andrew B. Yule ${ }^{2}$ \\ ${ }^{1}$ Institut de Ciències del Mar, CMIMA (CSIC), Passeig Marítim de la Barceloneta 37-49, 08003 Barcelona, Spain \\ ${ }^{2}$ School of Ocean Sciences, University of Wales, Bangor, Menai Bridge, Gwynedd LL59 5EY, UK
}

\begin{abstract}
The small-scale spatial distribution of density and biomass of the crab Liocarcinus depurator off the Ebro delta was analysed using universal kriging (non-linear geostatistics), considering depth as an external trend. In order to understand the spatial distribution of crab size, a third variable was created from the residuals of the non-linear regression between biomass and density. Variogram analysis of crab density and residuals of the biomass/density relationship presented a quadratic relationship with depth, while biomass showed a linear relationship with depth. All experimental variograms were fitted to spherical models. The patch size (range) found was $10.64 \mathrm{~km}$ for density, $14.53 \mathrm{~km}$ for biomass and $20.49 \mathrm{~km}$ for the residual variables. The spatial distribution of 8 sediment variables (temperature, redox potential at 1 and $6 \mathrm{~cm}$ depth [R1 and R6], carbonate content $\left[\mathrm{CO}_{3}\right]$, median grain size $[\varphi]$, sediment sorting [IGSD: inclusive graphic standard deviation] and organic matter content $[\mathrm{OM}]$ ) was studied. The maps obtained were compared with those calculated for the biological variables of $L$. depurator using Mantel and partial Mantel tests. Distribution characteristics of this species were significantly affected by most sediment variables considered, particularly by temperature, organic matter content and redox potential, although overall the correlation level was low, coinciding with the generalist ecological role and opportunistic behaviour of the species. Density and biomass, as well as residuals, presented a negative correlation with the sorting coefficient (IGSD) and with carbonates. In relation to IGSD, high densities of $L$. depurator were found in homogeneous sediments. Residuals (size structure of the population) were significantly correlated with grain size $(\varphi)$, with larger individuals occurring in finer sediments, while juveniles were preferably found in areas with very fine sand sediments. Both density and biomass presented significant positive correlations with the redox potential, indicating that the species favoured well-oxygenated sediments with a low organic content.
\end{abstract}

KEY WORDS: Geostatistics - Sediment variables - Liocarcinus depurator · Portunidae - Kriging · Mantel test $\cdot$ Temperature $\cdot$ Granulometry $\cdot$ Spatial distribution

\section{INTRODUCTION}

Patchy distributions of individuals in marine benthic systems can be related to local environmental conditions as well as to biotic factors such as competition and predation (Whittaker \& Levin 1977, Palmer 1988). For example, predators may more readily locate prey items in some habitats than others and hence reduce prey abundance differentially between habitats (Southern \& Lowe 1968). Additionally, the physical environment, for example temperature, salinity and sediment characteristics, has been shown to determine smallscale distribution in benthic crabs (e.g. Vernberg \& Vernberg 1983). Sediment grain size, which is deter- 
mined by hydrodynamic sorting mechanisms, and organic content are considered the 2 most influential characteristics determining occupancy by marine benthos (Gray 1981).

Surveys designed to assess the density of benthic organisms often do not take into account the spatial heterogeneity of the habitats or try to account for it by implementing differential habitat sampling, often referred to as stratified random sampling (Petitgas 1996). However, empirical evidence suggests that the existence of structure at different spatial scales does induce autocorrelation between pairs of samples, producing biases in density estimates (Petitgas 1996). Further, there is interest in ecology to quantify the structure of spatial dependence among samples in order to gain knowledge on the spatial structure of benthic organisms and the factors determining such structure. In this context, the use of geostatistics has been advocated by several authors as a useful tool to describe and model spatial dependence in benthic organisms (e.g. Sullivan 1991, Petitgas 1993, 1994, 1996, Maynou et al. 1996, Maynou 1998, Fernandes \& Rivoirard 1999, Rivoirard et al. 2000). Conan (1985) first introduced geostatistical techniques to marine biology, using kriging to produce unbiased biomass estimates and mapping isodensity contours of the scallop Placopecten magellanicus.

Most applications of geostatistics to marine organisms and fisheries are focused on fish species and were recently reviewed by Petitgas (1993, 2001). However, the application of geostatistics to crustacean populations is still limited (Freire et al. 1991b, 1992, Simard et al. 1992, González-Gurriarán et al. 1993, Maynou et al. 1996, 1998, Maynou 1998). Additionally, most applications in geostatistics are restricted to linear geostatistics and ordinary kriging, without taking into account possible data transformation or correlation with environmental variables to improve parameter estimates and reduce variance. Furthermore, when the variable under study is not stationary, nonlinear geostatistics are clearly more appropriate (Cressie 1991).

Differences in spatial distribution according to biological categories, such as number of juveniles, females, males, berried females, etc., has been widely reported in the crustacean literature (e.g. Abelló et al. 1990, 1997, Ardizzone et al. 1990, Rossi \& Costantini 2000), although it has received less research effort within the field of geostatistics (Comeau et al. 1998, Maynou et al. 1998, Lembo et al. 2000a). However, some studies suggest that different scales of spatial structuring (e.g. by geographic sectors, latitude or depth) may exist for a given species, as shown for the snow crab Chionoecetes opilio, for which an important spatial segregation was detected by sex and size in the
Gulf of Saint Lawrence using geostatistics (Comeau et al. 1998). The spatial structure of the shrimps Parapenaeus longirostris and Aristeus antennatus was studied by Lembo et al. (1999, 2000a,b) in the Tyrrhenian Sea from stratified, random, bottom-trawl data. These authors applied cross-variograms and co-kriging to the data, considering depth as an auxiliary variable, which allowed a density estimation closer to the known pattern for this species, thus overcoming the limitations presented by ordinary kriging. These analyses were able to detect 3 zones with higher densities within the sampling area, which persisted in the same localities from 1995 to 1997 (Lembo et al. 1999). The procedure significantly increased the fit of the models, and decreased the standard error of the estimates. In the case of A. antennatus, Lembo et al. (2000a,b) also analysed the variable 'percentage of females larger than median length', and in P. longirostris the 'number of recruits $\mathrm{km}^{-2}$ ' through disjunctive kriging techniques.

Liocarcinus depurator is the most common and abundant brachyuran crab on trawlable muddy bottoms of the continental shelf in the western Mediterranean (Mori \& Zunino 1987, Abelló et al. 1988, 2002, Abelló 1993, González-Gurriarán et al. 1993). Given its abundance and the fact that it is a predator of mobile benthic and epibenthic organisms, it may prove to be a 'keystone' species in the community (Abelló \& Cartes 1987, Mori \& Manconi 1989). L. depurator is distributed along the eastern Atlantic coasts from Mauritania to Norway and throughout the Mediterranean (Zariquiey-Álvarez 1968, d'Udekem d'Acoz 1999), with a wide bathymetric range (continental shelf and upper slope). It occurs on several types of substrata, especially on muddy and sandy-mud bottoms (Minervini et al. 1982). Abelló (1993) showed a trend for crab sizes of both sexes to increase with increasing depth in a population off the Catalan coast. Recruitment took place mainly on the shallow continental shelf (25 to $50 \mathrm{~m}$ ), although the bathymetric range where recruitment could take place was wider. For L. depurator, geostatistical analyses have been applied by Freire et al. (1991a) and González-Gurriarán et al. (1993) off the Atlantic Iberian coasts and by Ungaro et al. (1999) in the SW Adriatic Sea. Both studies reported that L. depurator aggregates spatially in patches, both on the Galician continental shelf and in the Adriatic Sea. Depth, bottom steepness and sediment characteristics have been shown in these studies as factors affecting the spatial structure of $L$. depurator.

The objectives of the present work were to analyse the spatial distribution of Liocarcinus depurator in a population located off the Ebro delta in the western Mediterranean, and to relate the distribution patterns to observed environmental parameters in order to try 
to understand the spatial variability presented by the populations of this species, under the hypothesis that sediment characteristics significantly affect distribution parameters. Furthermore, this study aimed at illustrating the use of non-linear geostatistics and how this technique could be more widely applied to study spatial patterns of benthic species.

\section{MATERIALS AND METHODS}

Survey. A trawl survey (GEODELTA) was conducted over muddy bottoms off the Ebro delta continental shelf and slope $\left(40^{\circ} 20^{\prime} \mathrm{N}\right.$ to $41^{\circ} 00^{\prime} \mathrm{N}$, NE Spain, Fig. 1) with the RV 'García del Cid'. A regular grid, $1 \times 2$ nautical miles, was set parallel to the coast and a start location for each tow was randomly selected within each cell; 1 area in the southern region was not sampled due to the presence of oil-rig platforms. Sampling was conducted between 7 and 15 April 1994 with a total of 72 stations. The water depth varied from 83 to $713 \mathrm{~m}$ across the sampling sites. The northern part of the study area is characterised by a narrow shelf (8 to 10 $\mathrm{km}$ wide) with a gentle slope seawards that is cut by deep submarine canyons. South of $\sim 40^{\circ} 50^{\prime} \mathrm{N}$, the shelf becomes progressively wider ( 38 to $40 \mathrm{~km}$ ) and the slope steeper, with fewer submarine canyons. The sampling gear was a modified otter trawl drawn by a single warp (Maireta System Trawl: Sardà et al. 1994).

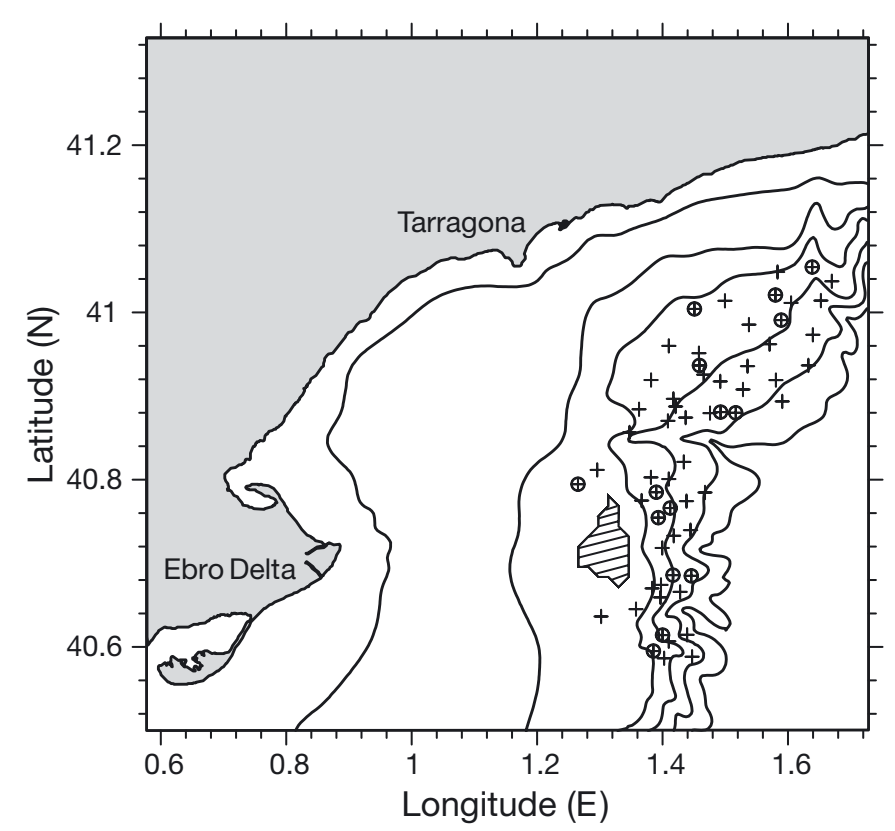

Fig. 1. Study area showing locations of sampling stations (+) and sites where sediment samples were also taken $(\oplus)$. Contour lines represent depth isolines (left to right: coast line, 50, 100, 200, 400, 600 and $800 \mathrm{~m}$ depth). Hatching: non-trawlable bottom in vicinity of oil-rig platform
The cod-end stretched-mesh width was $12 \mathrm{~mm}$ in order to retain small individuals not normally caught by commercial fishing gear. The working dimensions of the trawl mouth were measured acoustically (SCANMAR) and averaged $13.4 \times 2.0 \mathrm{~m}$. The effective trawling time was $15 \mathrm{~min}$ and trawls were always run parallel to the depth contours. Towing speed varied between 2.3 and 2.7 knots (mean 2.5 knots). The start and end locations for each tow were recorded by GPS. The actual surface covered by each tow was computed from the GPS and SCANMAR readings. The total Liocarcinus depurator catch was counted and weighed, and the carapace length of each crab was measured. Density was computed from the total surface covered by each tow as number of individuals $\mathrm{ha}^{-1}$ and biomass as $g \mathrm{ha}^{-1}$. We considered 3 biological variables: density, biomass, and the residuals of the non-linear relationship between biomass and density, as an indicator of the relative size of individuals (see Fig. 2). This latter variable was used to overcome the problem of the small number of individuals caught in some samples, which did not allow the study of the spatial structure of further biological categories such as mean carapace size, number of females or number of males.

Sediment samples were collected using a Van Veen grab (Gray 1981) every second trawl haul, except in the continental shelf area at depths shallower than $200 \mathrm{~m}$, where sediment heterogeneity was presumably higher and 1 sediment sample was collected per tow. Sediment samples were analysed following the methodology of Maynou \& Sardá (1997) and Alonso et al. (1999). The surface sediment temperature $\left(T,{ }^{\circ} \mathrm{C}\right)$ and the redox potential at 1 and $6 \mathrm{~cm}$ from the sediment surface (R1 and R6, mV) were measured onboard ship using a double-joint, multimeter electrode (Orion Research Model 250A) immediately after sample collection. Sediment samples were stored at $-20^{\circ} \mathrm{C}$ for later laboratory analyses. The redox potential for marine sediments is usually negative, with higher negative values for more reduced sediments generally indicating sediments containing large amounts of organic matter. Normally, undisturbed marine sediments are structured in layers, and redox potential measurements in the deeper levels $(6 \mathrm{~cm}$ in our case) show higher negative values than those near the surface ( $1 \mathrm{~cm}$ in our case). Grain-size analysis was carried out on the sediment samples using a SEDIGRAPH 5000D for the fine-grained fraction $(<50 \mu \mathrm{m})$ and sedimentation-tube analysis for the coarse-grained fraction. For each sample, the proportions of sand (62.5 to $1000 \mu \mathrm{m}$ ), silt $(2$ to $62.5 \mu \mathrm{m})$ and clay $(0.06$ to $2 \mu \mathrm{m})$ were determined. The grain-size distribution of each sample was summarised also by its median, $\varphi=-\log _{2}$ (median grain size in $\mathrm{mm}$ ) (Gray 1981), and its sorting coefficient IGSD (inclusive graphic standard deviation; Gray 
1981). Low IGSD values indicate well-sorted sediments and high values poorly sorted sediments (Maynou \& Sardá 1997). The carbonate content $\left(\%\right.$ of $\mathrm{CO}_{3}$ by volume) of each sediment sample was determined using a Bernard calcimeter, following the methodology of Vatan (1967).

Statistical methods. Mantel's normalised $r$-statistic (Mantel 1967) can be used to determine the degree of correlation between 2 distance matrices, A and B, using any of the distance coefficients available in the ecological literature (Legendre \& Legendre 1998). Mantel's $r$-statistic was used as an additional test for the existence of spatial autocorrelation, by constructing a matrix, A, of geographical distances (using Euclidean distance) and a matrix, B, of biological distances (using the Manhattan coefficient of dissimilarity). The partial Mantel test was used to analyse the residual correlation between 2 matrices, A and B, by extracting the correlation due to a distance matrix, C, which may represent a common environmental factor structuring Matrices A and B: in this case depth. The significance of both the Mantel and partial Mantel coefficients were tested by permutation (Manly 1985, Legendre 2000). The Mantel test was performed using the library 'vegan' of the software package $R$, and the partial Mantel test was programmed by one of the authors (F. M.) in R following the methods outlined in Legendre (2000). The correlation coefficient used in the Mantel test was Kendall's (Sokal \& Rohlf 1995).

The fundamentals of geostatistics, with emphasis on the non-linear methods employed here, have been explained in several publications (e.g. Cressie 1991, Diggle et al. 2003). Linear geostatistics were not used in this work because of 'non-stationarity' in the data (see e.g. Cressie 1991 on the assumptions and limitations of linear geostatistics). Considering the variable $Z_{i}$ observed at $x_{i}$ spatial locations, where $i=1, \ldots, n$, as the realisation of a spatial process $S(x)$, the expectation of $\mu(x)$ is:

$$
\mu(x)=\sum_{k=1}^{p} f_{k}(x) \beta_{k}+S(x)
$$

where $\mu(x)$ is an appropriate transformation of $Z_{i}$ to ensure normality, $f_{k}(x)$ is a set of spatially-referenced $p$ explanatory variables, and $\beta_{k}$ are the coefficients of these explanatory variables. This can be viewed as a generalised linear model (McCullagh \& Nelder 1983) in a spatial context (Diggle et al. 2003) or as a generalisation of universal kriging to non-Gaussian data (Cressie 1991). The procedure applied to fit this method was to find a suitable transformation of the raw data to ensure normality and then model the autocorrelation function $\gamma(h)$ of the spatial process $S(x)$ taking into account the explanatory variables $f(x)$. The range of the semivariogram can be interpreted as the dis- tance beyond which no effects of spatial covariance among the samples exist (Maynou et al. 1998). In the absence of spatial autocorrelation, the mathematical expectation of the semivariograms, the sample variance and the semivariogram appears flat (pure nugget effect (Maynou et al. 1998). The term 'range' indicates the size of the patches in which the population is structured (Sokal \& Oden 1978).

We used, as dependent $Z_{i}$ variables, 2 measures of Liocarcinus depurator abundance (ind. $\mathrm{ha}^{-1}$ and $\mathrm{g} \mathrm{ha}^{-1}$ ) and the residuals of the non-linear regression between ind. $\mathrm{ha}^{-1}$ and $\mathrm{g} \mathrm{ha}^{-1}$ as an index of crab size. As explanatory variables, $f_{k}(x)$, we used a linear trend in $x$, a quadratic trend in $x$, a linear trend with depth, and a quadratic trend with depth. The general Box-Cox set of transformations was used. The autocorrelation function $\gamma(h)$ of the spatial process $S(x)$ was fitted by weighted least-squares (as recommended by Cressie 1991 for Gaussian random processes). The analyses were conducted using the software package R (Ihaka \& Gentleman 1996) and the library 'geoR' (Ribeiro \& Diggle 1999).

The degree of correlation between the sediment and the biological variables was analysed between the kriging estimates with the Mantel test (Mantel 1967) and the partial Mantel test (Smouse et al. 1986). Additionally, Mantel's spatial correlograms were calculated to estimate the degree of spatial correlation in relation to the scale (distance) between abundance and each environmental variable (Legendre \& Legendre 1998). This statistic was calculated with the use of the 'ncf' package ( $\mathrm{R}$ language [Ihaka \& Gentleman 1996]), with 10000 permutations.

\section{RESULTS}

Density and biomass of Liocarcinus depurator were significantly correlated (biomass $=5.69 \times$ abundance $^{1.31}, \mathrm{r}^{2}=0.9074, \mathrm{df}=69, \mathrm{p}<0.0001$ ) by non-linear regression (Fig. 2). Despite the low number of samples, the exponent $b=1.31$ of the fitted relationship biomass $=\mathrm{a} \times$ density $^{b}$ is similar to that found in previous studies (approximately 4/3: Burton 1998) and therefore the relationship fitted in this study can be considered to be within the usual estimated ranges, thus validating the variable residual. The residuals were not normal (tested using the Box-Cox methodology [Sokal \& Rohlf 1995]), neither were any of the variables. No empirical transformation improved the quality of the data and we used universal kriging as a particular case of the general model given in Eq. (1), because kriging is robust to departures from normality (Cressie 1991).

The results of the Mantel and partial (removing the effect of depth) Mantel tests (Table 1) indicated that 


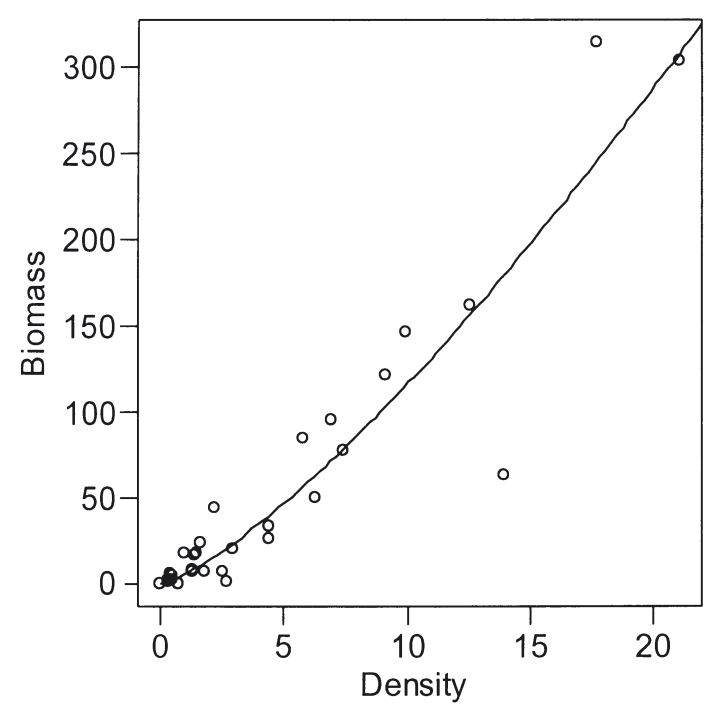

Fig. 2. Liocarcinus depurator. Non-linear regression between abundance and biomass with fitted regression line (biomass = $5.69 \times$ abundance $^{1.31}, \mathrm{r}^{2}=0.9074$ )
Table 1. Liocarcinus depurator. Results of Mantel test and partial Mantel (removing effect of depth) using Kendall's correlation index. Significant spatial correlations $(0.95<p<0.05)$ are in bold, negative correlation in italics. Temp.: temperature; R1R6: vertical difference between between R1 and R6 (redox potential); $\mathrm{CO}_{3}$ : carbonate content; $\varphi$ : median grain size; ISGD: sorting coefficient (inclusive graphic standard deviation); OM: organic matter

\begin{tabular}{|lrrrr|}
\hline Variable & \multicolumn{2}{c}{ Simple } & \multicolumn{2}{c|}{ Partial } \\
& r & $p$ & $r$ & $p$ \\
\hline Abundance & $\mathbf{0 . 1 6 6}$ & $<\mathbf{0 . 0 0 1}$ & $\mathbf{0 . 1 3 9}$ & $\mathbf{0 . 0 0 7}$ \\
Biomass & $\mathbf{0 . 1 3 7}$ & $\mathbf{0 . 0 1 5}$ & $\mathbf{0 . 1 1 7}$ & $\mathbf{0 . 0 2 2}$ \\
Residuals & $\mathbf{0 . 1 4 2}$ & $\mathbf{0 . 0 0 7}$ & $\mathbf{0 . 1 2 1}$ & $\mathbf{0 . 0 1 9}$ \\
Temp. & 0.0670 & 0.0509 & 0.0306 & 0.1859 \\
R1 & 0.0260 & 0.2421 & 0.0304 & 0.2161 \\
R6 & 0.0596 & 0.0779 & 0.0632 & 0.0751 \\
R1R6 & -0.0333 & 0.7680 & -0.0303 & 0.7423 \\
CO 3 & $\mathbf{0 . 1 4 4 1}$ & $\mathbf{0 . 0 0 2 1}$ & $\mathbf{0 . 1 2 7 5}$ & $\mathbf{0 . 0 0 3 6}$ \\
$\varphi$ & 0.0522 & 0.1348 & 0.0229 & 0.2914 \\
IGSD & $\mathbf{0 . 2 1 5 4}$ & $\mathbf{0 . 0 0 0 1}$ & $\mathbf{0 . 2 0 0 6}$ & $\mathbf{0 . 0 0 0 0}$ \\
OM & -0.0519 & 0.9109 & $-\mathbf{0 . 0 6 7 9}$ & $\mathbf{0 . 9 6 9 7}$ \\
\hline
\end{tabular}

density, biomass, residuals, carbonates and the sorting index (IGSD) were spatially structured. By removing the effect of depth (partial Mantel test), spatial structure was still present, although there was a general decrease in spatial correlation $(r)$, indicating that the spatial structure found did not depend solely on depth.

The parameters of the different fitted semivariogram models (spherical, Gaussian and exponential) (Table 2) indicated that the spherical model was the most statistically appropriate when considering an automatic model selection, since the minimising function always presented the lowest values. Density and residuals showed a quadratic relationship with depth, while the relationship of biomass with depth was linear. The patch size (range) was $10.64 \mathrm{~km}$ for density, $14.53 \mathrm{~km}$ for biomass and $20.49 \mathrm{~km}$ for the residuals.

The variation in the range obtained with each model (no trend, 1st with depth and 2nd with depth) for all variables (Table 2) indicated the possible values of the patch size, allowing comparison with previous studies which used only linear geostatistics with no trend (Freire et al. 1993, González-Gurriarán et al. 1993, Ungaro et al. 1999). The degree of spatial dependence (Robertson \& Freckmann 1995) was high and varied between 82 and $100 \%$, indicating that most of the total variance could be explained by the variogram models. Fig. 3
Table 2. Liocarcinus depurator. Models fitted with weighted leastsquares to experimental semivariograms produced for each biological variable. Sp. d.: spatial departure indicating \% of variance explained by the model: $(1-$ nugget/sill $) \times 100 ; 1$ st depth indicates linear trend with depth, 2nd depth quadratic trend; sph: spherical; gau: Gaussian exp: exponential; Min. funct.: value of the minimising function. Model selected for kriging is in bold

\begin{tabular}{|c|c|c|c|c|c|}
\hline Factor & Nugget & Sill & Sp. d. & Range & Min. funct. \\
\hline \multicolumn{6}{|l|}{ Abundance } \\
\hline \multicolumn{6}{|l|}{ No trend } \\
\hline sph & 2.13 & 16.69 & 87 & 21.88 & 12967 \\
\hline gau & 4.64 & 14.16 & 67 & 10.66 & 13364 \\
\hline exp & 0.00 & 21.20 & 100 & 10.25 & 13576 \\
\hline \multicolumn{6}{|l|}{ 1st depth } \\
\hline sph & 2.39 & 10.28 & 77 & 14.80 & 7368 \\
\hline gau & 4.20 & 8.51 & 51 & 7.50 & 7418 \\
\hline \multicolumn{6}{|l|}{ 2nd depth } \\
\hline sph & 1.88 & 10.52 & 82 & 14.53 & 6335 \\
\hline gau & 3.80 & 8.66 & 56 & 7.43 & 6396 \\
\hline \multicolumn{6}{|l|}{ Biomass } \\
\hline \multicolumn{6}{|l|}{ No trend } \\
\hline sph & 73.66 & 3282.38 & 98 & 14.49 & 376640297 \\
\hline $\exp$ & 0.00 & 3531.88 & 100 & 6.16 & 418281717 \\
\hline \multicolumn{6}{|l|}{ 1st depth } \\
\hline sph & 0.00 & 2661.70 & 100 & 10.64 & 298068268 \\
\hline \multicolumn{5}{|l|}{ 2nd depth } & 318271642 \\
\hline \multicolumn{6}{|l|}{ Residuals } \\
\hline \multicolumn{6}{|l|}{ No trend } \\
\hline exp & 0.00 & 359.57 & 100 & 8.25 & 17172209 \\
\hline $\begin{array}{l}\text { 1st depth } \\
\text { sph }\end{array}$ & 39.84 & 296.14 & 87 & 20.16 & 16579790 \\
\hline 2nd depth & 43.18 & 291.86 & 85 & 20.49 & 15649224 \\
\hline
\end{tabular}



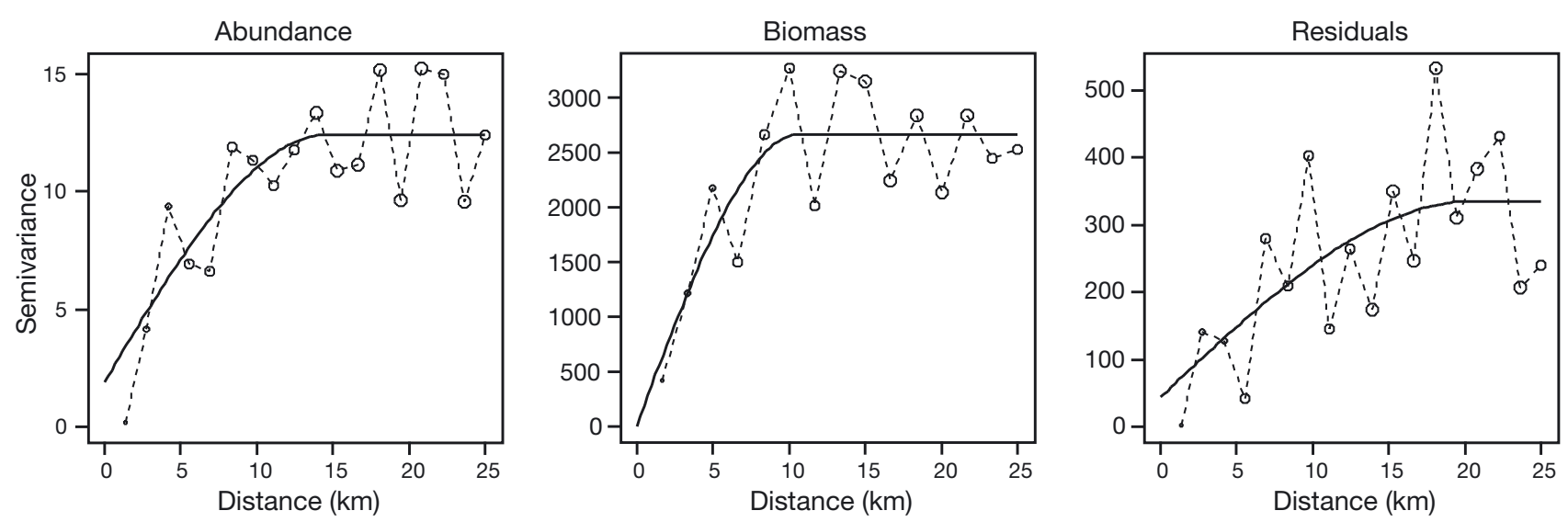

Fig. 3. Liocarcinus depurator. Experimental semivariogram and respective spherical model fitted with weighted least-squares (size of the markers is proportional to number of pairs divided by median pair number)
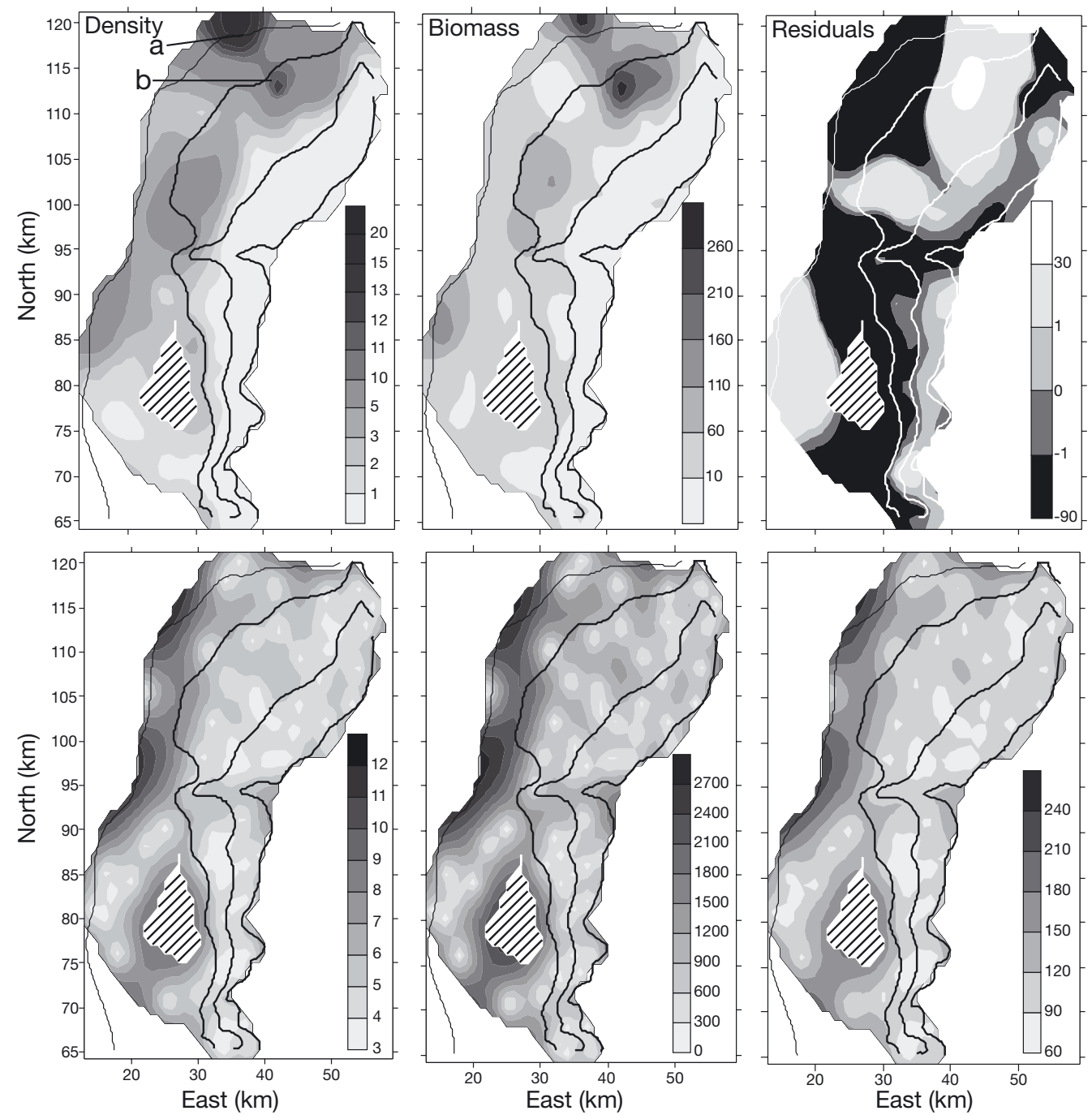

Fig. 4. Liocarcinus depurator. Maps of the biological variables (density [ind. ha $\left.{ }^{-1}\right]$, biomass $\left[\mathrm{g} \mathrm{ha}^{-1}\right.$ ] and residuals), produced by kriging with external trend (top graphs), and estimation variances (bottom graphs); the graphs of residuals and variances are dimensionless. Contour depth lines from left to right: 100, 200, 400 and $600 \mathrm{~m}$. Hatched area corresponds to oil-rig platform. $\mathrm{a}, \mathrm{b}: 2$ patches with greatest densities. See Table 2 for model values 
presents the experimental semivariograms with their selected model fits.

Kriging maps with external trend predictions and estimation variances are presented in Fig. 4 for the 3 biological variables studied. Sparse distribution of the variances of the kriging estimates can be observed for all variables. In the north of the study area, 2 main patches of distribution were found in both density and biomass around the 100 and $200 \mathrm{~m}$ depth contours (patches a and b, respectively, in Fig. 4). A central area (around $200 \mathrm{~m}$ depth) of high density and biomass was also observed close to the main submarine canyon. Overall, Liocarcinus depurator showed greater density and biomass in shallow than in deeper waters within the sampling area. The residuals map shows that, especially in the northern area with highest density and biomass, greater concentrations of small individuals were present at shallower depths (patch a; Fig. 5), while larger individuals were found in the deeper area (patch b; Fig. 5). For depths greater than 400 m, the residuals map should be interpreted with care, since density was lower, and the residuals obtained may not be completely representative.

A hierarchical procedure similar to that used for the biological variables was used to determine the most appropriate spatial model for the sediment variables. For brevity, only the best model is presented in Table 3. Depth, temperature, carbonates and IGSD were fitted to a linear semivariogram model. Organic matter and R1 showed a spherical semivariogram model whereas $\varphi$ presented a Gaussian model, all of them with a quadratic trend with depth. Note that the actual range of a Gaussian model is range $\times \sqrt{3}$ (Cressie 1991). For both R1 and $\varphi$, kriging with external drift was calculated, while for the remaining variables ordinary kriging was performed (Fig. 6). Sediment temperature showed a trend with depth, with higher temperatures at greater depths within the range represented $\left(12.2\right.$ to $\left.13.6^{\circ} \mathrm{C}\right)$, due to the effect of water salinity on density, since slightly warmer but more saline waters were found at

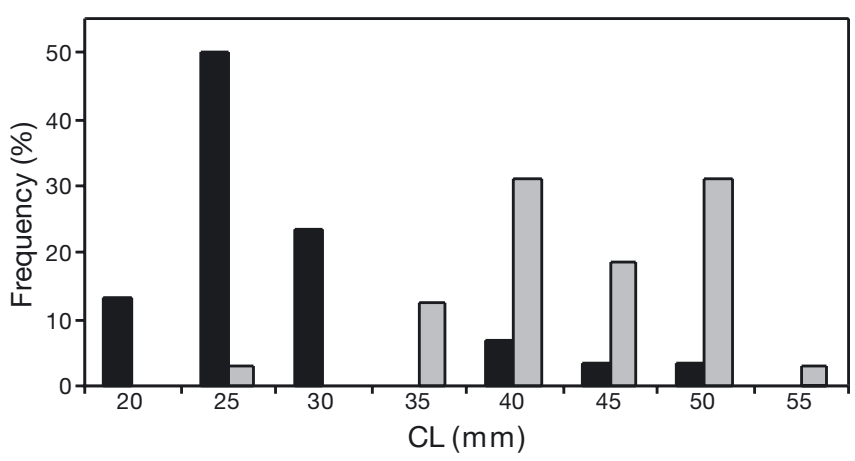

Fig. 5. Liocarcinus depurator. Relative frequency of carapace length (CL) in 2 trawls from which a similar number of crabs was measured from patches a (black bars, 30 crabs) and b (grey bars, 32 crabs), in the kriged density map (Fig. 4). Note differences in size distributions between the 2 trawls

greater depths. The redox potential at $1 \mathrm{~cm}$ depth (R1) showed maximum values ( $\mathrm{R} 1$ from -8 to $-310 \mathrm{mV}$ ) close to the canyon area and in the southernmost area, although the overall distribution was rather patchy. R6 also showed a patchy distribution (maximum R6 was $-105 \mathrm{mV}$ and minimum was $-370 \mathrm{mV}$ ). Carbonates and IGSD showed a similar pattern of distribution, with lower values in the north (carbonate content range: 23.0 to $41.1 \%$; IGSD range: 1.7 to 3.5 ) and higher values in the south. The organic matter content of the sediment showed a positive trend with increasing depth, and was particularly high around the deep canyon in the study area. Even though temperature, R1, R6 and $\varphi$ did not present a significant spatial autocorrelation when using both Mantel tests ( $p>0.05)$, the analysis of the semivariograms of R1 and $\varphi$ clearly showed spatial structure (Table 3).

The Mantel test using Kendall's correlation index showed that all sediment variables were significantly correlated with at least 1 biological variable, but the degree of overlap (r) varied greatly (Table 4). The spa-

Table 3. Models fitted with weighted least-squares to experimental semivariograms produced for each sediment variable. Sp. d.: spatial departure, indicating \% of variance explained by the model: $(1-$ nugget/sill $) \times 100$; 1 st depth indicates linear trend with the covariate depth, 2nd depth quadratic trend. Range/slope indicates slope in linear (lin) models, and range in the other models. Further abbreviations as in Tables 1 \& 2

\begin{tabular}{|c|c|c|c|c|c|c|c|}
\hline Variable & Model & Covariate & Nugget & Sill & Sp. d. & Range/slope & Min. funct. \\
\hline Depth & $\operatorname{lin}$ & No trend & 372.361 & & & 1999.519 & $1.74 \times 10^{12}$ \\
\hline Temp. & $\operatorname{lin}$ & No trend & 0.041 & & & 0.005 & 0 \\
\hline $\mathrm{R} 1$ & sph & 2nd depth & 0.000 & 3253.730 & 100 & 5.950 & 316937573 \\
\hline $\mathrm{R} 6$ & $\operatorname{lin}$ & No trend & 2140.783 & & & 1.000 & 144683791 \\
\hline R1R6 & lin & No trend & 1555.870 & & & 1.000 & 65579879 \\
\hline $\mathrm{CO}_{3}$ & lin & No trend & 15.910 & & & 0.540 & 11218 \\
\hline$\varphi$ & gau & 2nd depth & 0.000 & 2.005 & 100 & 7.534 & 110 \\
\hline IGSD & $\operatorname{lin}$ & No trend & 0.124 & & & 0.012 & 2 \\
\hline OM & $\mathrm{sph}$ & 2nd depth & 0.994 & 1.989 & 100 & 20.113 & 131.6 \\
\hline
\end{tabular}



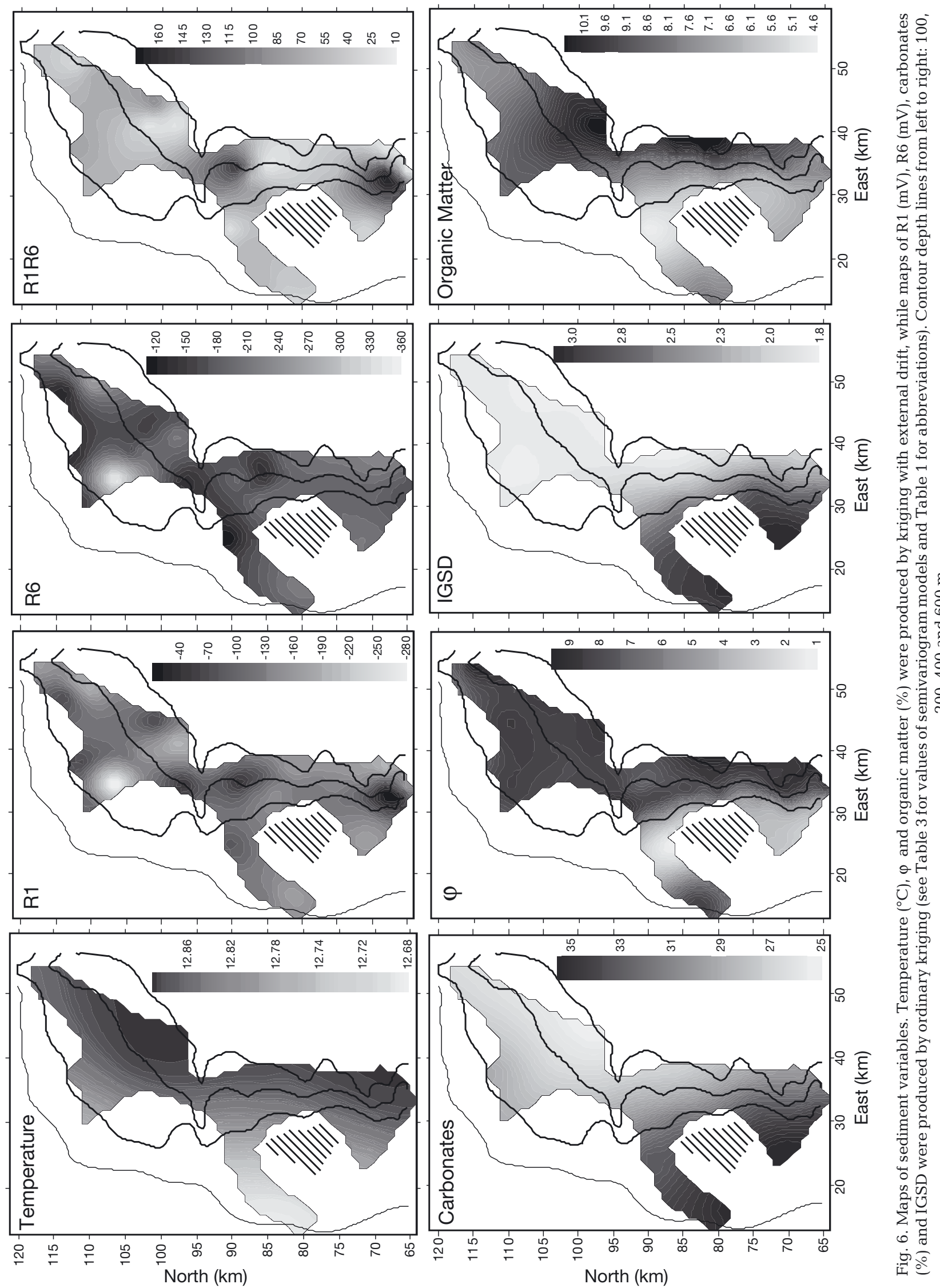
tial overlaps of R1R6 (vertical difference in the redox potential between 1 and $6 \mathrm{~cm}$ ) and IGSD with density, carbonates with biomass and carbonates and IGSD with residuals were not significantly correlated using the Mantel test, but when extracting the effect of depth (partial Mantel test) these correlations became significant. The opposite occurred between carbonates and $\varphi$ with density, in which the correlation was due only to the spurious effect of depth, since when depth was extracted from the relationship the overlap became nonsignificant (Table 4). These results reinforce the importance of the incorporation of depth into the analysis, in particular when using the partial Mantel test.

The partial Mantel test results indicated that temperature, redox potential (R1 and R6) and organic matter were positively correlated with both density and biomass of Liocarcinus depurator, while the sorting coeffi-

Table 4. Liocarcinus depurator. Mantel and partial Mantel correlations of estimated kriging values (limited to sampling area) between abundance (ind. ha $\left.{ }^{-1}\right)$, biomass $\left(\mathrm{g} \mathrm{ha}^{-1}\right)$ and residuals with sediment variables (temperature, R1, R6, R1R6, carbonates, $\varphi$, IGSD) and with each other. $\mathrm{p}<0.05$ indicates significant overlapping. Significant spatial correlation $0.95<$ $\mathrm{p}<0.05$ ) is in bold, negative correlation in italics. Abbreviations as in Table 1

\begin{tabular}{|c|c|c|c|c|}
\hline \multirow{2}{*}{$\begin{array}{l}\text { Sediment } \\
\text { variable }\end{array}$} & \multicolumn{2}{|c|}{ Mantel } & \multicolumn{2}{|c|}{ Partial Mantel } \\
\hline & $\mathrm{r}$ & $\mathrm{p}$ & $\mathrm{r}$ & $\mathrm{p}$ \\
\hline \multicolumn{5}{|l|}{ Abundance } \\
\hline Temp. & 0.3826 & 0.0000 & 0.1885 & 0.0011 \\
\hline $\mathrm{R} 1$ & 0.2875 & 0.0000 & 0.1567 & 0.0032 \\
\hline R6 & 0.4105 & 0.0000 & 0.2729 & 0.0000 \\
\hline R1R6 & -0.0700 & 0.9070 & -0.1047 & 0.9814 \\
\hline $\mathrm{CO}_{3}$ & 0.0581 & 0.0479 & -0.0474 & 0.9269 \\
\hline$\varphi$ & 0.1050 & 0.0226 & -0.0484 & 0.8116 \\
\hline IGSD & -0.0178 & 0.6448 & -0.1231 & 0.9968 \\
\hline $\mathrm{OM}$ & 0.3673 & 0.0000 & 0.1619 & 0.0002 \\
\hline \multicolumn{5}{|l|}{ Biomass } \\
\hline Temp. & 0.3059 & 0.0000 & 0.1363 & 0.0070 \\
\hline $\mathrm{R} 1$ & 0.2392 & 0.0001 & 0.1246 & 0.0106 \\
\hline $\mathrm{R} 6$ & 0.4017 & 0.0000 & 0.2874 & 0.0000 \\
\hline R1R6 & -0.1068 & 0.9824 & -0.1344 & 0.9972 \\
\hline $\mathrm{CO}_{3}$ & 0.0198 & 0.2463 & -0.0657 & 0.9794 \\
\hline$\varphi$ & 0.0639 & 0.1052 & -0.0592 & 0.8681 \\
\hline IGSD & -0.0728 & 0.9505 & -0.1574 & 0.9998 \\
\hline $\mathrm{OM}$ & 0.3067 & 0.0000 & 0.1334 & 0.0003 \\
\hline \multicolumn{5}{|l|}{ Residuals } \\
\hline Temperature & 0.3619 & 0.0000 & 0.2307 & 0.0000 \\
\hline $\mathrm{R} 1$ & 0.1946 & 0.0009 & 0.0895 & 0.0508 \\
\hline R6 & 0.2438 & 0.0001 & 0.1177 & 0.0162 \\
\hline R1R6 & 0.0024 & 0.4619 & -0.0074 & 0.5340 \\
\hline $\mathrm{CO}_{3}$ & 0.0143 & 0.2998 & -0.0579 & 0.9623 \\
\hline$\varphi$ & 0.2036 & 0.0000 & 0.1188 & 0.0132 \\
\hline IGSD & -0.0333 & 0.7642 & -0.0982 & 0.9798 \\
\hline $\mathrm{OM}$ & 0.3180 & 0.0000 & 0.1747 & 0.0000 \\
\hline
\end{tabular}

Table 5. Liocarcinus depurator. Kendall's correlation index $\left(r_{k}\right)$ of partial Mantel test of estimated kriging values (limited to sampling area) between abundance (ind. ha ${ }^{-1}$ ), biomass $\left(\mathrm{g} \mathrm{ha}^{-1}\right)$ and residuals with sediment variables (temperature, R1, R6, R1R6, carbonates, $\varphi$, IGSD and OM). Only significant correlations are indicated. Positive values indicate significant overlap, negative values (italics) significant exclusion. Abbreviations as in Table 1

\begin{tabular}{|lccc|}
\hline & Abundance & Biomass & Residuals \\
\hline Temp. & 0.19 & 0.14 & 0.23 \\
R1 & 0.16 & 0.12 & \\
R6 & 0.27 & 0.29 & 0.12 \\
R1R6 & -0.10 & -0.13 & \\
$\mathrm{CO}_{3}$ & & -0.07 & -0.06 \\
$\varphi$ & & & 0.12 \\
IGSD & -0.12 & -0.16 & -0.10 \\
OM & 0.16 & 0.13 & 0.17 \\
\hline
\end{tabular}

cient IGSD and the variable R1R6 were negatively correlated with them, thus indicating that these sediment variables are determinant for $L$. depurator distribution (Fig. 7, Table 5). Residuals, the indirect index of size structure, were significantly correlated with all sediment variables except for R1 and R1R6; grain size $\varphi$ was only significantly correlated with residuals, thus indicating that it only affected the differential distribution of adults and juveniles, but not that of biomass or density (Table 4).

Fig. 8 shows the spatial Mantel correlogram between the environmental variables and distance. Significant correlations were observed only for shorter distances in all cases, except with the redox potential (R1, R6 and R1R6), which was correlated at larger distances, and depth, which showed significant correlation for both shorter and larger distances. Temperature, carbonates and IGSD showed significant correlations with larger distances (15 to $20 \mathrm{~km}$ ).

\section{DISCUSSION}

Simple and partial Mantel tests were able to detect the occurrence of spatial structure in density and biomass of Liocarcinus depurator, as well as in density/ biomass residuals and in sediment variables, even when the effect of depth was eliminated from the relationship. However, the performance of a Mantel test to check the occurrence of a significant spatial structure was non-conclusive for all variables, since some sediment variables (R1 and $\varphi$ ) were not significantly spatially correlated according to this test, but presented clearly structured semivariograms. The inability to detect spatial correlation in these cases may be due to the lower number of samples (36 samples) or may point to the low statistical power of the Mantel test. 


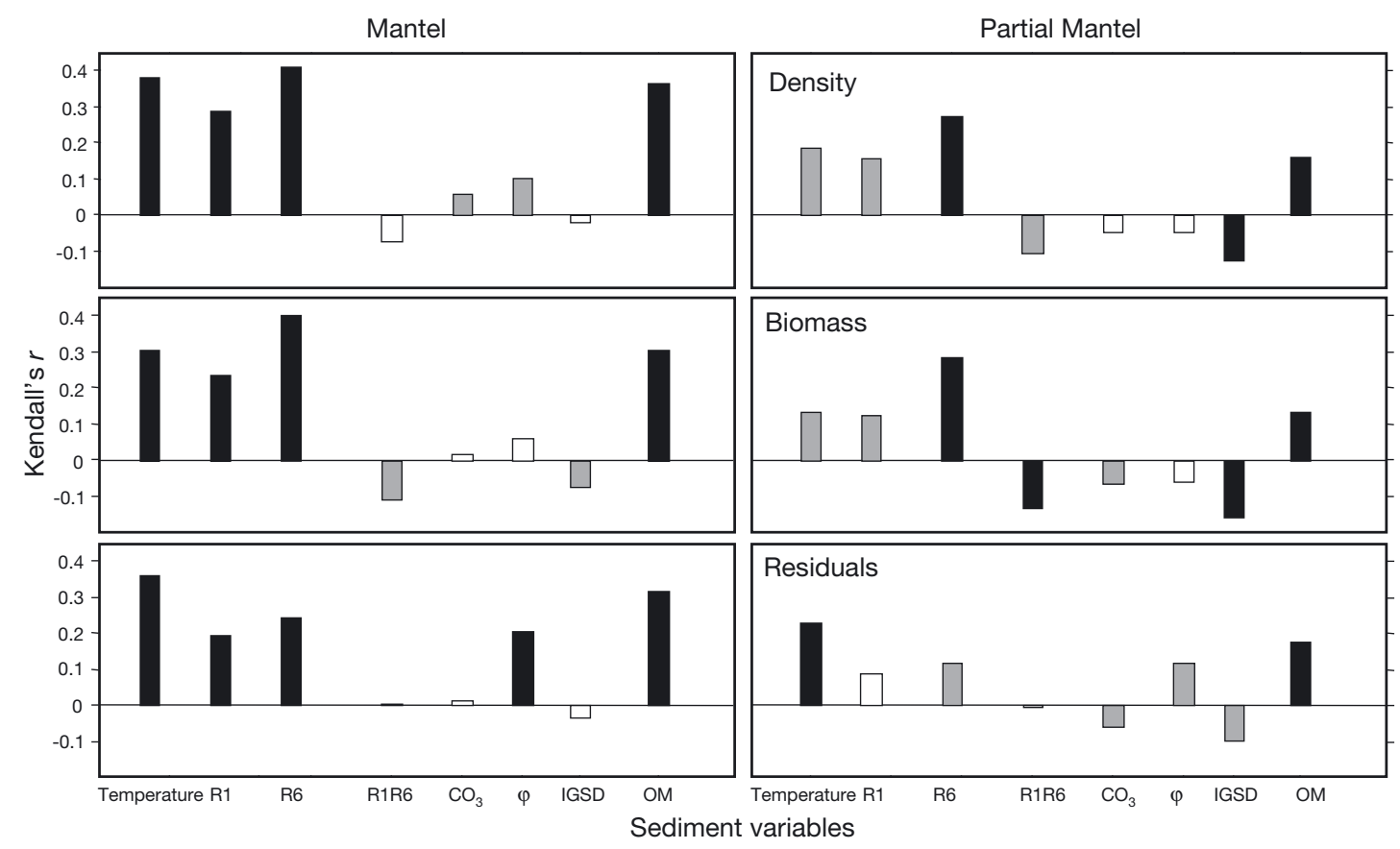

Fig. 7. Liocarcinus depurator. Significant spatial correlations of biological variables with sediment variables (black bars: abundance; grey bars: biomass; white bars: residuals). Abbreviations as in Table 1
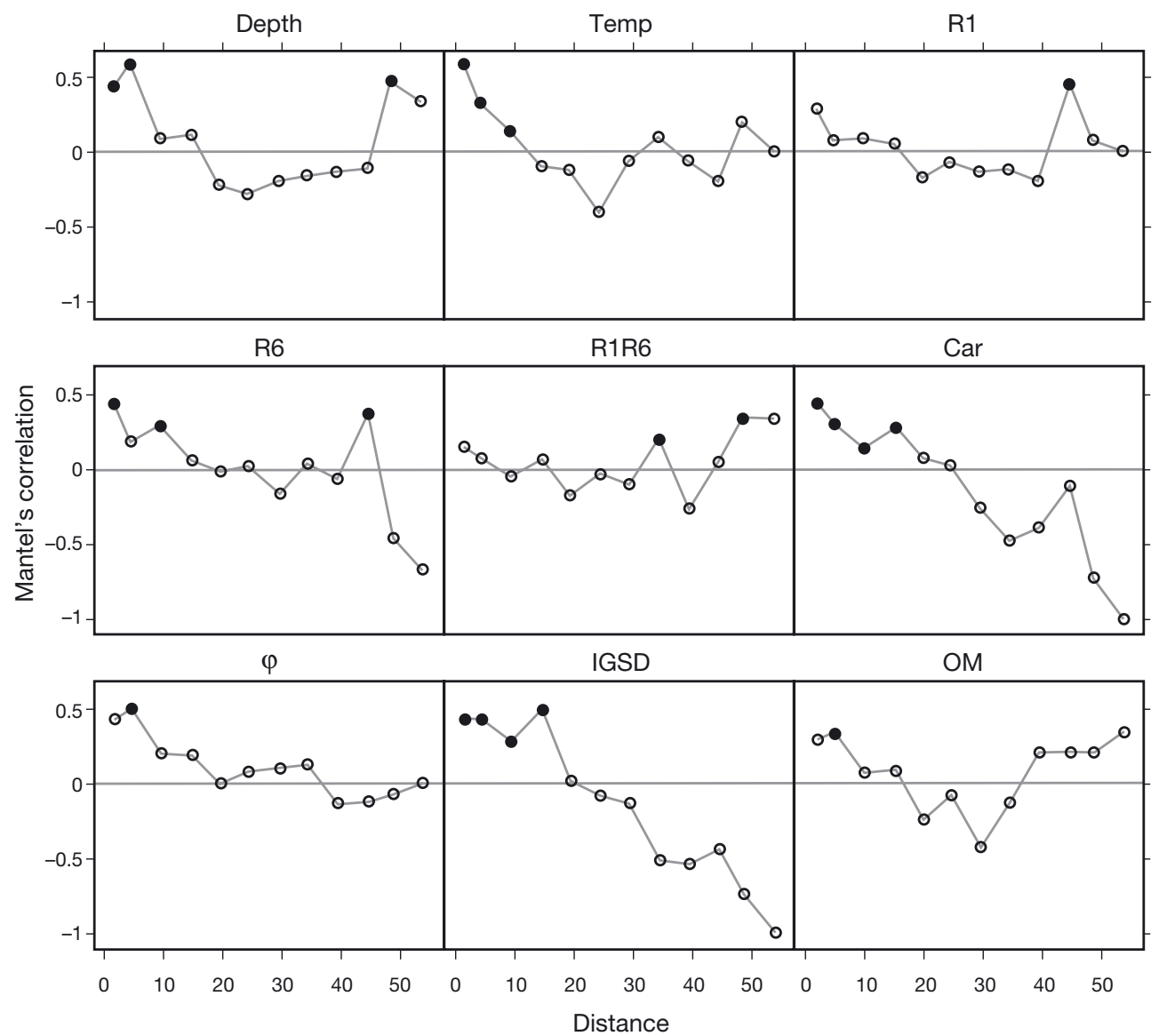

Fig. 8. Liocarcinus depurator. Mantel spatial correlogram between crab density and environmental variables. •: significant correlations (10 000 permutations, $\mathrm{p} \leq 0.05)$; O: not significant; Car: carbonates. Other abbreviations as in Table 1 
Automatic, semiautomatic or manual semivariogram model selection has been the subject of discussion in the literature (Cressie 1991, Petitgas 1996, Rivoirard et al. 2000). In this study, it was observed that the minimising function from weighted least-squares allowed the selection of the most appropriate spatial model, although previous information on the ecology of the species was also fundamental.

Depth is known to play a key role in structuring Liocarcinus depurator populations, in regard to both density and size structure (Mori \& Zunino 1987, Abelló et al. 1988, Abelló 1993). González-Gurriarán et al. (1993) reported that although depth may be the major largescale physical factor affecting distribution patterns, it did not appear to be determinant within their study area (the Galician coast). This was not the case in our study, where depth played a major role in the spatial distribution of the crab. González-Gurriarán et al. (1993) concluded that sediment and oceanographic conditions were also important variables affecting the spatial distribution of the species. Previous geostatistical studies with other species also showed depth to be an important covariant in geostatistical fisheries studies (Sullivan 1991, Simard et al. 1992). When comparing the different spatial models fitted to the calculated semivariograms for the biological variables studied, the best model (that with the smallest minimising function) was the spherical model, a result obtained in previous crustacean studies (Freire et al. 1991b, GonzálezGurriarán et al. 1993, Maynou et al. 1998). Taking a depth trend into account clearly increased the precision of the model.

Previous studies of Liocarcinus depurator spatial structure in the Atlantic continental shelf (Galicia) detected patch sizes between 14 and 22 km (GonzálezGurriarán et al. 1993), which is in accordance with present results $(21.88 \mathrm{~km})$. Still, also in Galicia, a range of $3 \mathrm{~km}$ was estimated inside the Ria de Ferrol (Freire et al. 1993), a much smaller range than that observed in the adjacent Galician continental shelf by GonzálezGurriarán et al. (1993) and in the present study. These differences may be related to the fact that the Ria de Ferrol sampling area was approximately $15 \times 2 \mathrm{~km}$, and the maximum semivariogram distance was $8 \mathrm{~km}$; it would therefore not have been possible to detect a greater patch size in that study (Freire et al. 1993). Results from a geostatistical study in the SW Adriatic Sea by Ungaro et al. (1999) detected a patch size (effective range) of $160 \mathrm{~km}\left(0.48^{\circ} \times 60 \mathrm{~min} \times 1.852 \mathrm{~km}\right.$ $=53.34 \mathrm{~km}$, which for the exponential model used in that study would mean an effective range of $3 \times$ range [Cressie 1991] $=53.34 \mathrm{~km} \times 3=160 \mathrm{~km})$ in an autumn survey and $69.67 \mathrm{~km}\left(0.209^{\circ} \times 60 \mathrm{~min} \times 1.852 \mathrm{~km} \times 3=\right.$ $69.67 \mathrm{~km}$ ) in a spring survey. This is much larger than the patch size observed either in our study or in the
Galician study (González-Gurriarán et al. 1993). However, Ungaro et al. (1999) did not publish sufficient details to allow interpretation of these large values.

Within the present study area, both density and biomass of Liocarcinus depurator were higher in the northern than in the southern area. The northern part is characterised by a narrow shelf (8 to $10 \mathrm{~km}$ width) and a gentle slope cut by deep submarine canyons, in contrast to the southern part where the shelf becomes progressively wider (38 to $40 \mathrm{~km}$ ) and the slope steeper. Submarine canyons tend to have high macrofaunal and meiofaunal biomass, in accordance with the higher rates of production and sedimentation from the shelf (Cartes et al. 1994, Maynou et al. 1996). The higher densities of $L$. depurator in the northern area may accordingly be related to increased prey resources, given the vicinity of the submarine canyons.

The creation of the residual variables (as an index of mean size of the individuals in a sample), extracted from the non-linear relationship between biomass and density, proved to be a useful and powerful tool for data analysis, and its application could be expanded to the field of fisheries, where the size of many non-target species is often not measured but data on species density and biomass per haul is available. This method is also valuable when the low number of specimens captured does not allow a valid size-frequency analysis. The present results indicate that the use of this variable was successful in discriminating between areas with different population-size structures, possible recruitment areas and overall spatial size-segregation trends. Thus, in areas with large densities, the smaller crabs clearly occupied shallower depths and larger individuals were concentrated in deeper areas. There is data in the literature on size relationships as a function of depth in many taxa, with patterns often difficult to generalise (Stefanescu et al. 1992, Carbonell et al. 2003). Previous studies on the distribution characteristics of $L$. depurator have also detected strong geographic variability in densities (Abelló 1986, 1993), as well as the key role of depth in structuring populations in regard to both density and size structure (Mori \& Zunino 1987, Abelló et al. 1988, Abelló 1993), with a tendency for small sizes to be found in shallower waters.

Sediment characteristics have been found to strongly influence occurrence and distribution of many benthic decapod crustaceans, especially of those with burrowing and burying habits (Atkinson \& Taylor 1988, Pinheiro et al. 1996, Comeau et al. 1998). In this study, the use of geostatistical procedures was fundamental in identifying which sediment variables may influence the distribution of Liocarcinus depurator. Distribution characteristics of this species were significantly affected by most sediment variables considered, particu- 
larly by temperature, organic matter content and redox potential, although overall the correlation level was low, thus emphasising the ecological strength and opportunistic behaviour of the species. Density and biomass, as well as residuals, presented a negative correlation with the sorting coefficient (IGSD) and with carbonates. In relation to IGSD, high densities of L. depurator were found in homogeneous sediments corresponding to low-energy areas. Residuals (e.g. size structure of the population) were significantly correlated with grain size $(\varphi)$, with larger individuals occurring in finer sediments, while juveniles were preferentially found in areas with very fine sand sediments. Minervini et al. (1982) showed that the distribution of $L$. depurator was mainly related to muddy sediments, in contrast with the congeneric species $L$. vernalis which was mainly found in sandy sediments. In the present study, both density and biomass displayed significant positive correlations with the redox potential, indicating that the species favours well-oxygenated sediments with low organic content.

Acknowledgements. We wish to thank all participants in the cruise GEODELTA on board RV 'García del Cid', especially its Chief Scientist, Dr. F. Sardà, for all help and facilities provided. This work was produced while M.M.R. had a PRAXIS $\mathrm{PhD}$ grant from the Portuguese government.

\section{LITERATURE CITED}

Abelló P (1986) Anàlisi de les poblacions de crustacis decàpodes demersals al litoral català: aspectes biològics del braquiur Liocarcinus depurator. $\mathrm{PhD}$ thesis, Institut de Ciències del Mar and Universitat de Barcelona, Barcelona

Abelló P (1993) Pautes de distribució de les espècies de la família Portunidae (Crustacea: Brachyura) als fons de substrat tou de la Mediterrània nord-occidental. Bull Inst Catal Hist Nat 61:59-68

Abelló P, Cartes JE (1987) Observaciones sobre la alimentación de Liocarcinus depurator (Brachyura : Portunidae) en el Mar Catalán. Investig Pesq (Barc) 51:413-419

Abelló P, Valladares FJ, Castellón A (1988) Analysis of the structure of decapod crustacean assemblages off the Catalan coast (North-West Mediterranean). Mar Biol 98:39-49

Abelló P, Villanueva R, Gili JM (1990) Epibiosis in deep-sea crab populations as indicator of biological and behavioural characteristics of the host. J Mar Biol Assoc UK 70: 687-695

Abelló P, Aagaard A, Warman CG, Depledge MH (1997) Spatial variability in the population structure of the shore crab Carcinus maenas (Crustacea: Brachyura) in a shallowwater, weakly tidal fjord. Mar Ecol Prog Ser 147:97-103

Abelló P, Carbonell A, Torres P (2002) Biogeography of epibenthic crustaceans on the shelf and upper slope off the Iberian Peninsula Mediterranean coasts: implications for the establishment of natural management areas. Sci Mar 66(Suppl 2):183-198

Alonso B, Ercilla G, Martínez-Ruiz F, Baraza J, Galimont A (1999) Pliocene-Pleistocene sedimentary facies at Site 976: depositional history in the northwestern Alboran Sea. In: Zahn R, Comas MC, Klaus A (eds) Proc ocean drilling program scientific Results, Vol. 161. Ocean Drilling Program, College Station, TX, p 57-68

Ardizzone GD, Gravina MF, Belluscio A, Schintu P (1990) Depth-size distribution pattern of Parapenaeus longirostris (Lucas, 1846) (Decapoda) in the central Mediterranean Sea. J Crustac Biol 10:139-147

Atkinson RJA, Taylor AC (1988) Physiological ecology of burrowing decapods. In: Fincham AA, Rainbow PS (eds) Aspects of decapod crustacean biology, Vol 59. Oxford Science Publications, London, p 201-226

Burton RF (1998) Biology by numbers. Cambridge University Press, Cambridge

Carbonell A, Palmer M, Abelló P, Torres P, Alemany R, Gil de Sola L (2003) Mesoscale geographical patterns in the distribution of pandalid shrimps Plesionika spp. in the Western Mediterranean. Mar Ecol Prog Ser 247:151-158

Cartes JE, Company JB, Maynou F (1994) Deep-water decapod crustacean communities in the northwestern Mediterranean: influence of submarine canyons and season. Mar Biol 120 (2):221-229

Comeau M, Conan GY, Maynou F, Robichaud G, Therriault JC, Starr M (1998) Growth, spatial distribution, and abundance of benthic stages of the snow crab (Chionoecetes opilio) in Bonne Bay, Newfoundland, Canada. Can J Fish Aquat Sci 55:262-279

Conan GY (1985) Assessment of shellfish stocks by geostatistical techniques. Int Counc Explor Sea Comm Meet K:30

Cressie NAC (1991) Statistics for spatial data. John Wiley \& Sons, New York

Diggle PJ, Ribeiro JR, Christensen OF (2003) An introduction to model based geostatistics. Lecture notes in statistics. In: Möller J (ed) Spatial statistics and computational methods. Springer-Verlag, New York, p 1-127

d'Udekem d'Acoz C (1999) Inventaire et distribution des crustacés décapodes de l'Atlantique nord-oriental, de la Méditerranée et des eaux continentales adjacentes au nord de $25^{\circ} \mathrm{N}$. Patrimoines Naturels, Museum National d'Histoire Naturelle de Paris, Paris

Fernandes PG, Rivoirard J (1999) A geostatistical analysis of the spatial distribution and abundance of cod, haddock and whiting in the North Scotland. In: Gómez-Hernández J, Soares A, Froidevaux R (eds) GeoENVII. Kluwer Academic Publishers, Dordrecht, p 201-212

Freire J, Fernández L, González-Gurriarán E (1991a) Spatial distribution of decapod crustaceans in the Galician continental shelf (NW Spain) using geostatistical analysis. Int Counc Explor Sea Comm Meet K:4

Freire J, González-Gurriarán E, Olaso I, Fernández L (1991b) Análisis geoestadístico de la distribución espacial de Plesionika heterocarpus y Solenocera membranacea (Crustacea: Decapoda) en la plataforma continental de Galicia (NW España). Bol Inst Esp Oceanogr 7:79-88

Freire J, González-Gurriarán E, Olaso I (1992) Spatial distribution of Munida intermedia and M. sarsi (Crustacea: Anomura) on the Galician continental shelf (NW Spain): application of geostatistical analysis. Estuar Coast Shelf Sci 35:637-648

Freire J, Fernández L, Muiño R, González-Gurriarán E (1993) Análisis geoestadístico de la distribución espacial de las poblaciones de crustáceos y peces megabentónicos en la Ría de Ferrol (Galicia NO España). Publ Espec Inst Esp Oceanogr 11:259-267

González-Gurriarán E, Freire J, Fernández L (1993) Geostatistical analysis of spatial distribution of Liocarcinus depurator, Macropipus tuberculatus and Polybius henslowii (Crustacea: Brachyura) over the Galician continental shelf (NW Spain). Mar Biol 115:453-461 
Gray JS (1981) The ecology of marine sediments. Cambridge University Press, Cambridge, UK

Ihaka R, Gentleman R (1996) R: a language for data analysis and graphics. J Comput Graph Stat 5:299-314

Legendre P (2000) Comparison of permutation methods for the partial correlation and partial Mantel tests. Journal of Statistical Computation and Simulation 67:37-73

Legendre P, Legendre L (1998) Numerical ecology. Elsevier, Amsterdam

Lembo G, Silecchia T, Carbonara P, Acrivulis A, Spedicato MT (1999) A geostatistical approach to the assessment of the spatial distribution of Parapenaeus longirostris (Lucas, 1846) in the central-southern Tyrrhenian Sea. Crustaceana 72:1093-1095

Lembo G, Silecchia T, Carbonara P, Contegiacomo M, Spedicato MT (2000a) Localization of nursery areas of Parapenaeus longirostris (Lucas, 1846) in the central-southern Tyrrhenian Sea by geostatistics. Crustaceana 73(1):39-51

Lembo G, Tursi A, D'Onghia G, Spedicato MT, Maiorano P, Silecchia T (2000b) Spatio-temporal distribution of Aristeus antennatus (Risso, 1816) (Crustacea: Decapoda) in the northwestern Ionian Sea: preliminary data using geostatistics. In: Bertrand JA, Relini G (eds) Demersal resources in the Mediterranean. Ifremer, Plouzane, p 173185

Manly BFJ (1985) The statistics of natural selection. Chapman \& Hall, New York

Mantel N (1967) The detection of disease clustering and a generalized regression approach. Cancer Res 27:209-220

Maynou F, Conan GY, Cartes JE, Company JB, Sardà F (1996) Spatial structure and seasonality of decapod crustacean populations on the northwestern Mediterranean slope. Limnol Oceanogr 41:113-125

Maynou F, Sardà F (1997) Nephrops norvergicus population and morphometrical characteristics in relation to substrate heterogeinity. Fish Res 30:139-149

Maynou F (1998) The application of geostatistics in mapping and assessment of demersal resources. Nephrops norvegicus (L.) in the northwestern Mediterranean: a case study. Sci Mar 62(Suppl 1):117-133

Maynou FX, Sardà F, Conan GY (1998) Assessment of the spatial structure and biomass evaluation of Nephrops norvegicus (L.) populations in the northwestern Mediterranean by geostatistics. ICES J Mar Sci 55:102-120

McCullagh P, Nelder JA (1983) Generalized linear models. Chapman \& Hall, London

Minervini R, Giannotta M, Falcia L (1982) A preliminary report on the decapod crustaceans in the estuarine area of the Tiber. Quad Lab Tecnol Pesca 3:305-318

Mori M, Manconi R (1989) Alimentazione di Liocarcinus depurator (L.) (Crustacea: Decapoda) in Mar Ligure. Boll Mus Ist Biol Univ Genova 53:69-79

Mori M, Zunino P (1987) Aspects of the biology of Liocarcinus depurator (L.) in the Ligurian Sea. Investig Pesq (Barc) 51: 135-145

Palmer M (1988) Epibenthic predators in marine meiofauna: separating predation, disturbance and hydrodynamic effects. Ecology 69:1251-1259

Petitgas P (1993) Geostatistics for fish stock assessments: a review and an acoustic application. ICES J Mar Sci 50: 285-298

Petitgas P (1994) Spatial strategies of fish populations. Int Counc Explor Sea Comm Meet D:14

Petitgas P (1996) Geostatistics and their applications to fish- eries survey data. In: Megrey BA, Moksness E (eds) Computers in fisheries research. Chapman \& Hall, London, p 113-142

Petitgas P (2001) Geostatistics in fisheries survey design and stock assessment: models, variances and applications. Fish Fish 2:231-249

Pinheiro MAA, Fransozo A, Negreiros-Fransozo ML (1996) Ditribution patterns of Arenaeus cribarius (Lamarck, 1818) (Crustacea, Portunidae) in Fortaleza Bay, Ubatuba (SP), Brazil. Rev Bras Biol 56:705-716

Ribeiro JR, Diggle PJ (1999) geoS: a geostatistical library for S-PLUS. Department of Mathematics and Statistics, Lancaster University, Lancaster

Rivoirard J, Simmonds J, Foote KG, Fernandes PG, Bez N (2000) Geostatistics for estimating fish abundance. Blackwell Science, Oxford

Robertson GP, Freckmann DW (1995) The spatial distribution of nematode trophic groups across a cultivated ecosystem. Ecology 765:1425-1432

Rossi L, Costantini ML (2000) Mapping the intra-habitat variation of leaf mass loss rate in a brackish Mediterranean lake. Mar Ecol Prog Ser 203:145-159

Sardá F, Cartes JE, Company JB (1994) Spatio-temporal variations in megabenthos abundance in three different habitats of the Catalan deep-sea (Western Mediterranean). Mar Biol 120:211-219

Simard Y, Legendre P, Lavoie G, Marcotte D (1992) Mapping, estimating biomass, and optimizing sampling programs for spatially autocorrelated data: case study of the northern shrimp (Pandalus borealis). Can J Fish Aquat Sci 49: $32-45$

Smouse PE, Long JC, Sokal RR (1986) Multiple regression and correlation extensions of the Mantel test of matrix correspondence. Syst Zool 35:627-632

Sokal RR, Oden NL (1978) Spatial autocorrelation in biology. 1. Methodology. Biol J Linn Soc 10:199-228

Sokal RR, Rohlf FJ (1995) Biometry: the principles and practice of statistics in biological research, 3rd edn. WH Freeman, New York

Southern H, Lowe V (1968) The pattern of distribution of prey and predation in tawny owl territories. J Anim Ecol 37: 75-97

Stefanescu C, Rucabado J, Lloris D (1992) Depth-size trends in western Mediterranean demersal deep-sea fishes. Mar Ecol Prog Ser 81:205-213

Sullivan P (1991) Stock abundance estimation using depthdependent trends and spatially correlated variation. Can J Fish Aquat Sci 48:1691-1703

Ungaro N, Marano G, Vlora A, Passarella G (1999) Distribution patterns of two species of swimming crabs (Portunidae), Liocarcinus depurator (L.) and Macropipus tuberculatus (Roux), in the southwestern Adriatic Sea (Mediterranean Sea). In: Von Vaupel Klein JC, Schram FR (eds) The biodiversity crisis and Crustacea: Proc Fourth Int Crustacean Congr, Amsterdam, The Netherlands, July 20-24, 1998. AA Balkema, Rotterdam, p 131-138

Vatan A (1967) Manuel de sédimentologie. Technip, Paris

Vernberg FJ, Vernberg WB (eds) (1983) The biology of crustacea. Environmental adaptions, Vol 8. Academic Press, New York

Whittaker R, Levin S (1977) The role of mosaic phenomena in natural communities. Theor Popul Biol 12:117-139

Zariquiey-Álvarez R (1968) Crustáceos decápodos ibéricos. Investig Pesq (Barc) 32:1-510

Submitted: July 2, 2003; Accepted: March 11, 2004

Proofs received from author(s): July 12, 2004 